\title{
Julie Doucet: del underground al desencanto y la experimentación gráfica
}

\author{
Magda Mengual Morata y Jordi Giner Monfort
}

Recibido: 15.05.2021 — Aceptado: 10.06.2021

\section{Titre / Title / Titolo}

Julie Doucet: de l'underground au désenchantement et à l'expérimentation graphique

Julie Doucet: from the underground to disenchantment and graphic experimentation

Julie Doucet: dall'underground al disincanto e alla sperimentazione grafica

\section{Abstract / Resumen / Résumé / Riassunto}

La obra de la dibujante canadiense Julie Doucet, conocida por Dirty Plotte y My New York Diary, se reconoce por su oscuridad y abigarramiento. Después de unos años en los que llegó a colaborar con publicaciones como Wimmen's Comix, Twisted Sisters o Weirdo, abandonó progresivamente los postulados hegemónicos del cómic y su estilo personal reconocible para adentrarse en nuevas formas de experimentación gráfica. Detrás de esta decisión parece que había razones varias, entre las que destaca el hecho de renunciar a un mercado hecho en gran medida por y para el público lector masculino. Si bien la transgresión ya era una característica asentada en Doucet, tanto en el lenguaje como en la imagen, sus últimos álbumes, en especial 365 Days, Elle Humour, My New New York Diary y Carpet Sweeper Tales, suponen un paso más en la experimentación visual y narrativa, tanto por el uso del collage como la pérdida de la importancia de la palabra escrita.

L'œuvre de la bédéiste canadienne Julie Doucet, auteur de Dirty Plotte et My New York Diary, est connue pour sa noirceur et l'entassement des objets. Après quelques années de collaboration avec des publications telles que Wimmen's Comix, Twisted Sisters ou Weirdo, elle abandonné progressivement les postulats hégémoniques de la bande dessinée et son style personnel reconnaissable pour entrer dans de nouvelles formes d'expérimentation graphique. Plusieurs raisons semblent être à l'origine de cette décision, parmi lesquelles le fait de renoncer à un marché largement fait par et pour le public masculin. Si la transgression était déjà une caractéristique établie de l'œuvre de Doucet, tant au niveau du langage que de l'image, ses derniers albums, notamment 365 Days, Elle Humour, My New New York Diary et Carpet Sweeper Tales, représentent un pas supplémentaire dans l'expérimentation visuelle et narrative, tant par l'utilisation du collage que par la perte de l'importance de l'écrit.
The work of Canadian cartoonist Julie Doucet, the author of Dirty Plotte and My New York Diary, is known for its somber tone and the density of space. After a few years in which she collaborated with publications such as Wimmen's Comix, Twisted Sisters and Weirdo, Doucet gradually abandoned the hegemonic postulates of comics and her recognisable personal style and adopted new forms of graphic experimentation. There seem to have been several reasons behind this decision, among them her wanting out of a market largely made by and for the male readers. While transgression was already an established feature of Doucet's work, both in language and image, her latest albums, especially 365 Days, Elle Humour, My New New York Diary and Carpet Sweeper Tales, represent a further step in visual and narrative experimentation, through both the use of collage and the loss of importance of the written word.

L'opera della fumettista canadese Julie Doucet, autrice di Dirty Plotte e My New York Diary, è nota per la sua oscurità e la densità dello spazio rappresentato. Dopo anni di collaborazione con pubblicazioni come Wimmen's Comix, Twisted Sisters e Weirdo, Doucet abbandonò gradualmente i postulati egemonici del fumetto e il suo riconoscibile stile personale per addentrarsi in nuove forme di sperimentazione grafica. Sembra che ci siano state diverse ragioni dietro questa decisione, tra cui la sua rinuncia a un mercato fatto in gran parte da e per un pubblico maschile. Se la trasgressione era già una caratteristica consolidata del lavoro di Doucet, sia nel linguaggio che nell'immagine, i suoi ultimi album, in particolare 365 Days, Elle Humour, My New New York Diary e Carpet Sweeper Tales, rappresentano un ulteriore passo nella sperimentazione visiva e narrativa, sia attraverso l'uso del collage che mediante la perdita di importanza della parola scritta.

\section{Palabras clave / Mots-clé / Key words I Parole chiave}

Julie Doucet, experimentación, underground, collage, autobiografía.

Julie Doucet, expérimentation, underground, collage, autobiographie.

Julie Doucet, experimentation, underground, collage, autobiography.

Julie Doucet, sperimentazione, underground, collage, autobiografia. 


\section{Introducción}

Julie Doucet (Quebec, 1965) es una creadora, ilustradora, editora, dibujante y poeta canadiense. Educada en un instituto católico, estudió artes plásticas en la Université du Québec à Montreal y se especializó en artes de impresión. Al mismo tiempo, empezaba a autoeditar sus creaciones en formato cómic y las distribuía no sólo para Canadá, sino también en el incipiente circuito de fanzines norteamericano, gracias a su incursión en Factsheet Five. De aquella época son su colaboración en el fanzine Tcbiize y la creación de la publicación que la daría a conocer internacionalmente: Dirty Plotte. En poco tiempo la obra de Doucet apareció en publicaciones como Screw (EE.UU.), S21'Art? (Francia), Wimmen's Comix, $R A W$, pero especialmente en Weirdo, la revista que la dio a conocer al gran público (Oksman, 2019: XXII). Su obra más conocida, Dirty Plotte, se puede traducir literalmente como dibujo sucio, aunque también hace referencia a la vagina en jerga quebecois, como la misma Doucet explica en el primer número de dicho fanzine (Byrnes, 31). Este hecho refleja el espíritu de sus cómics, al menos los publicados antes del año 2000. Precisamente la crudez de dibujo y mensaje, la suciedad y la oscuridad son lo que hace su estilo especial y reconocible: el predominio del negro, un trazo grueso y sucio, un lenguaje directo y sin concesiones al público lector, que al mismo tiempo es detallista y muy a menudo incómodo por los temas que trata, desde la menstruación (ver figura 1) al desmembramiento pasando por la autolesión. A menudo se ha calificado su cómic como confesional por sus características autobiográficas, pese a que en diferentes entrevistas Doucet ha aclarado que no todo lo que ha dibujado a lo largo de su carrera es autobiográfico, aunque sí buena parte de ello (Oksman, 2019b; Juno, 1997).

A lo largo de su carrera artística se podría decir que Julie Doucet ha llevado a cabo diferentes rupturas con el canon del cómic, como comprobaremos a continuación. No se trata solamente de rupturas estilísticas o temáticas, como innovar con el dibujo o las composicio- nes o tocar algunos temas poco habituales, lo cual por otra parte es bastante habitual en el cómic underground. Se trata, también, de rupturas que la acercan al cómic abstracto o poesía visual o que aportan innovaciones desde el punto de vista del contenido como las referencias autobiográficas o la vida cotidiana contada desde puntos de vista que resultan novedosos.

Julie Doucet dejó de dibujar cómics de manera voluntaria en 2010, después de dibujar e interpretar My new New York diary (2010). En parte, como ella misma confiesa, el abandono se debe a un proceso de agotamiento creativo y profesional, una cuestión de evolución (Juno, 1997). Esto mismo fue lo que la condujo a centrarse en la ilustración, la serigrafía y el collage, prácticas artísticas que había compaginado con el cómic durante toda su carrera creativa. Sin embargo, recientemente reconoció que había vuelto a dibujar tras el golpe que supuso el atentado de Charlie Hebdo (Oksman, 2019b; Mok, 2019: 203), aunque de momento este material no ha sido publicado.

\section{Metodología}

El examen de la obra de Doucet se ha llevado a cabo a partir de la lectura detenida y posterior análisis de sus publicaciones de mayor entidad posteriores a su decisión de abandonar el formato cómic. Así, se dejan al margen tanto sus publicaciones más conocidas (Dirty Plotte, My New York Diary) como las que ha autoeditado la misma autora a modo de fanzine en los últimos años, algunas de las cuales se pueden adquirir desde su página web. En definitiva, se trata de un repaso general a su última obra, con especial atención al material publicado en el siglo XXI, justo después de la crisis creativa que la llevó a reinventarse a través de diferentes rupturas.

$\mathrm{El}$ análisis del contenido se ha llevado a cabo a partir del formato, el contenido (lo que incluye tanto el texto como el dibujo) y el estilo, teniendo en cuenta el punto de partida que estaría representado por la que probablemente es su obra más conocida, My New York Diary. Además, se presta atención a la evolución de sus creaciones teniendo en cuenta los postulados hegemónicos 
del cómic, lo que podríamos denominar el canon de lo que se supone que es un cómic: imágenes yuxtapuestas en una secuencia deliberada, por usar la definición de McCloud (1994).

En lo que respecta a su obra editada, parte de los cómics de Doucet fueron traducidos al castellano inicialmente por la editorial l'Inrevés. Se trata de Si yo fuera hombre (1998), Diario de Nueva York (2001) y El caso Madame Paul (2002). Pero entre los años 2015 y 2017 la editorial Fulgencio Pimentel dio un salto cualitativo y editó su obra completa en cómic en dos partes: por un lado, el primer material que publicó en fanzines y las historias más o menos seriadas que publicó en los primeros 12 ejemplares de Dirty Plotte (1988-1997), además de mucha obra inédita, generalmente en formato corto. Por otra parte, la segunda parte que se inicia en 1994 y llega hasta 2016. Esta es la época en que Doucet vive en Nueva York (1991), Seattle (1992), Berlín (1995) y finalmente vuelve a Montreal (1998), donde se establece definitivamente (Oksman, 2019, pág. XXVIII). En este segundo volumen se incluyen obras de formato más largo como My New York Diary (1999), El affaire Madame Paul (2000) o My most secret desire (2006). Han quedado fuera de la recopilación de Fulgencio Pimentel su diario publicado originalmente por l'Association en 2004 y traducido al inglés por Drawn \& Quarterly en 2008 (Doucet, 2008) y toda su producción fuera de lo que se podría considerar cómic ortodoxo, principalmente a base de collages que ha continuado recopilando, de manera autoeditada o no. Este es el caso de Elle Humour (2006) o Carpet Sweeper Tales (2016), la última obra editada por Drawn \& Quarterly, compuesta íntegramente a base de recortes de fotonovelas de los años 60 .

\section{De la encarnación al desencanto}

Tratar de los cómics de Doucet pasa inevitablemente por los conceptos de feminismo, cuerpo y autobiografía. Se podría decir, siguiendo a Mari Luz Esteban (2004), que Doucet llevó a cabo entre 1988 y 2006 una producción de cómic feminista encarnado, es decir, centrada en sí misma, en su propio cuerpo y en la transgresión tanto temática y estilística como de las fronteras del propio cuerpo. Así, cuestiones como la menstruación, la masturbación, el vello, las mucosidades o el embarazo aparecían constantemente, mezclados con unos fondos lúgubres caracterizados por el horror vacui.

Lo que empezó siendo un experimento transgresor desde el punto de vista visual y literario, terminó encontrando su lugar, primero en publicaciones periódicas como Weirdo y, finalmente, en una editorial Drawn \& Quarterly, dirigida entonces por Chris Oliveros. Cabe decir que tanto la obra de Doucet como la de su editorial crecieron en paralelo (Moore, 2018: 200), se incorporaron nuevos autores y, especialmente, autoras (Anne D. Bernstein, Alice Sebold, Kate Beaton, Lynda Barry) o la misma editora, Peggy Burns. Se provocaba así un cambio no solo en el panorama editorial sino también en su público lector, conformado por un porcentaje equilibrado en la práctica entre hombres y mujeres, algo insólito hasta el momento en el panorama del cómic norteamericano (Jennings, 2015).

A pesar de ello, la obra de Doucet debe contextualizarse en un mercado de publicaciones altamente masculinizado, protagonizado por dibujantes de sexo masculino que dirigen su producto a lectores masculinos y que, por tanto, ofrecen un producto marcadamente masculino, lo que es patente en términos generales tanto en el cómic mainstream como en el underground (Moore, 2018). El reto de Doucet mientras duró su carrera de dibujante de cómic fue precisamente el de convivir con una cultura marcadamente masculina publicando material autobiográfico, o al menos centrado en el personaje que ella representaba y que muy probablemente sería consumido de manera mayoritaria por hombres. Además, lo hizo tocando temáticas que difícilmente se habían podido leer antes en un cómic, incluso underground, desde una perspectiva femenina y, aunque sin pretenderlo, también feminista. De hecho, Doucet nunca se consideró una dibujante abiertamente feminista. A pesar de que en la portada de Dirty Plotte adoptó como lema Comic Feministe de Mauvais Goût, ella misma se aleja- 


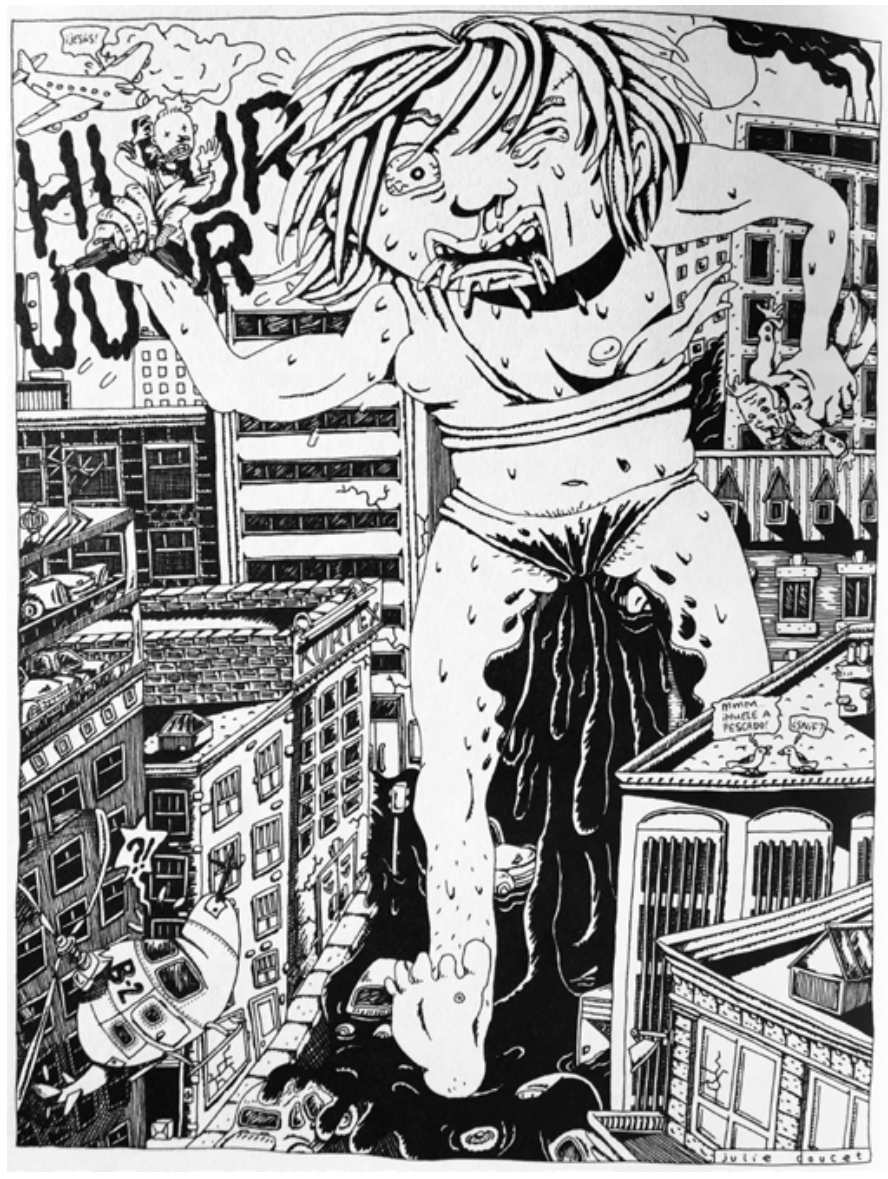

Figura 1. El monstruo de la menstruación Fuente: Doucet, 2015,pág. 22

ba inicialmente del feminismo -entendido este como el feminismo de segunda ola- aunque posteriormente sí que abrazaría los postulados feministas de la tercera ola (Galvan, 8; Byrn, 2019: 28; Mengual, 2020).

Según Anne Elizabeth Moore, entre las razones que explican el progresivo distanciamiento de Doucet respecto al cómic están el cansancio y los motivos económicos, pero también lo que ella llama all-boys crowd ${ }^{1}$, es decir, el colectivo tanto de creación como de consumo mayoritariamente masculino, y el vacío sistemático a que se somete tanto a las dibujantes de cómic como a sus lectoras (Moore, 20). A pesar de ello, su situación en Drawn \& Quarterly era diametralmente opuesta, dada su tradición de trabajo con autoras que hemos visto anteriormente. Incluso recibió halagos desde sus inicios, tanto desde la academia (caso de la comunicación de Heather Sinclair en The International Comic Arts Forum de 1998) como desde el feminismo (caso del grupo Le Tigre, que la situaron como referente del cómic en su canción Hot Topic). Sin embargo, esta denuncia no es ajena al resto de creadoras de cómic, que perciben menos ingresos que sus compañeros y además relatan haber vivido escenas en las que se pone en duda su profesionalidad o incluso su sexualidad (Moore, 17). Hasta en el propio entorno del feminismo, creaciones como las de Doucet se han considerado incómodas: era habitual que algunas librerías consideradas feministas rechazaran algunas de las primeras creaciones en forma de fanzine que Doucet les ofrecía (Moore, 202; Small Press Expo, 2018). Por tanto, el abandono del cómic se produjo por estas razones, pero también por otras de tipo personal: por una parte, una crisis creativa agravada por una mononucleosis que llegó justo en el momento en el que empezaba a recibir ingresos en forma de royalties, lo que le permitía vivir de sus creaciones (Juno, 59; Moore, 188; Mok, 198). Por otra parte, por la llegada de ayudas económicas del gobierno canadiense a la producción artística, lo que le permitió vivir más holgadamente y entrar a formar parte de un estudio de impresión (Moore, 193). Una última razón que explica su salida del cómic es la enorme dedicación en términos de esfuerzo y tiempo que se exigía para sus creaciones en formato cómic, algo que le impedía probar otros formatos (Mok, 204). Por tanto, su creación en formato cómic decreció y finalmente se transformó en un nuevo producto visual, tanto sobre papel como en formato animado, pero lejano de las convenciones estilísticas y de lenguaje que caracterizan al canon de la historieta y que habían dado a conocer su obra. Pese a que en 1997 ya advertía del inminente final de su carrera de dibujante de cómics (Juno, 1997), los coletazos en el mundo de la historieta seguirían prácticamente hasta 2010. 
365 Days: ritual de lo habitual

Con 365 Days, Julie Doucet llevó al ámbito de la publicación una práctica cotidiana que había mantenido durante varios años: el diario ilustrado. Por ello, se puede considerar que esta obra continúa su exploración autobiográfica, en este caso marcadamente fidedigna, aunque no profundice tanto en los aspectos emocionales o hechos significativos como en la rutina diaria. En este álbum se puede seguir su día a día, en ocasiones con un gran detalle, en otras ocasiones de una manera más laxa. El diario empieza el 30 de octubre de 2002 y termina el 5 de noviembre de 2003, con prácticamente una entrada diaria. El mero hecho de que se trate de un diario, inequívocamente autobiográfico, no como el resto de su obra anterior, entronca con la obra de autoras que han utilizado el cómic para narrar traumas relacionados con la violencia sexual, lo que para algunas autoras resignifica el cómic como herramienta política (Chute, 62 y ss.). Aunque este no sea el caso, en 365 Days Doucet muestra abiertamente sus posiciones políticas, por ejemplo, contra la guerra en Iraq o contra las creencias religiosas.

La exploración de la cotidianeidad que se puede observar en 365 days, además, supera el relato dirigido hacia un clímax resolutorio y se adentra en lo rutinario, en el aburrimiento cotidiano, lo que se opone al carácter de la narración organizada y con un guion establecido que es, en principio, lo que atrae la atención del público lector (Stark, 23). Por ello, se puede argumentar que con esta práctica se lleva a cabo una ruptura temática, al menos con el cómic que ella misma había dibujado hasta ese momento. Esta práctica se relaciona con el encarnamiento referido con anterioridad, pero a diferencia del que podemos encontrar en My New York Diary, lo que encontramos en esta bitácora es el reflejo de una mujer madura, preocupada por las dificultades propias de la vida adulta y su faceta profesional como la burocracia administrativa, los impuestos, las facturas o las fechas de entrega, como se puede observar en la figura 2. Además, se trata de una mujer madura y soltera cuyo centro de interés no es encontrar pareja, con lo que presenta un modelo alejado de lo que parte de la sociedad espera como arquetipo de la feminidad. Según Jessica Stark, existe una relación estrecha entre la cultura del aburrimiento y la subjetividad femenina expresada en el diario y simbolizada en el tipo ideal del ama de casa. En este sentido, Doucet explora los límites del cómic como hecho masculino, que construye la narración a partir de gestas extraordinarias que tienden a culminar en un clímax que, en este caso, no existe (Stark, 27 y ss.).

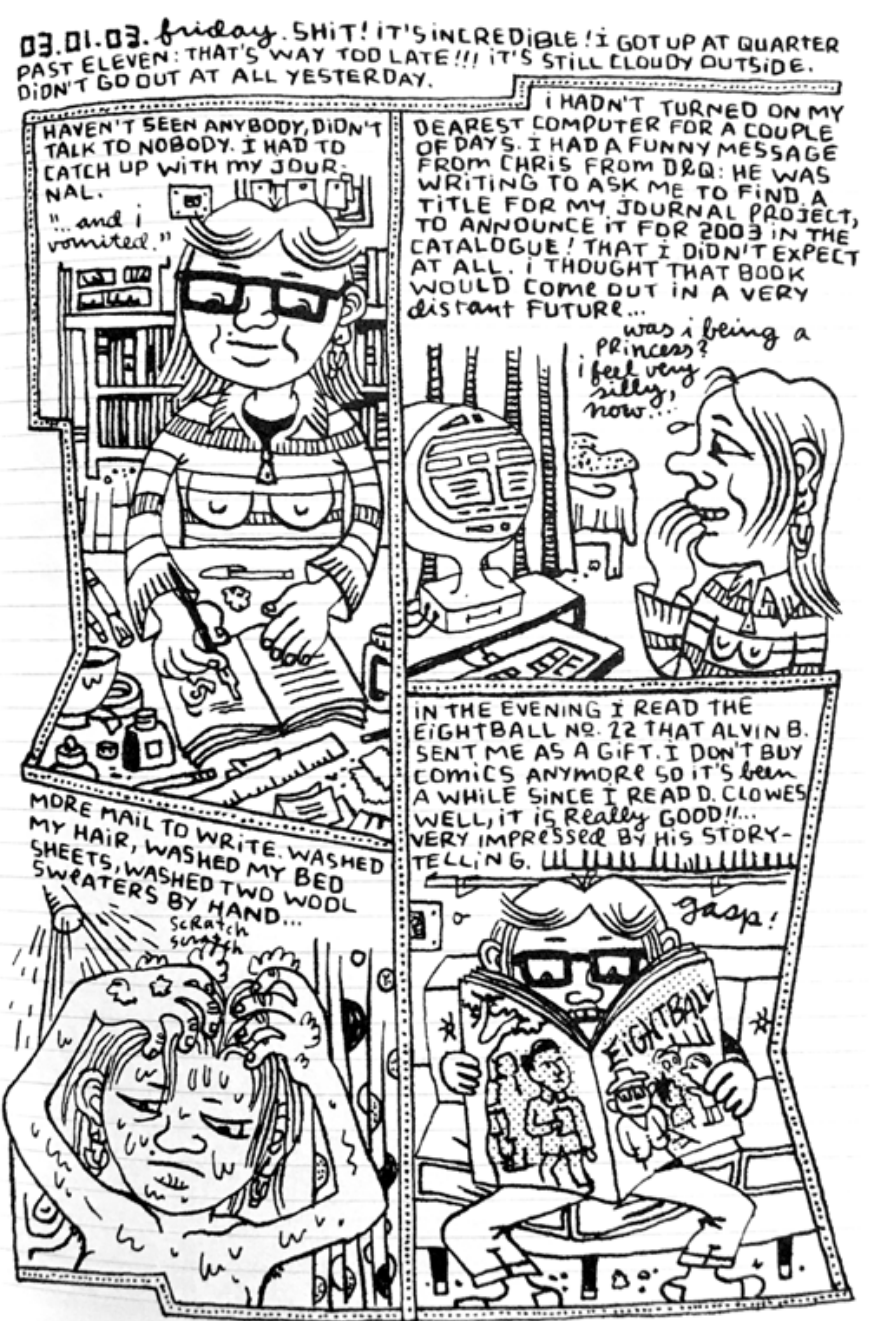

Figura 2.03.01.03

Fuente: Doucet, 2007, pág. 76 
Desde el punto de vista estilístico, 365 days continua con la tendencia de su obra anterior a un menor oscurantismo y un trazo más fino, pero al mismo tiempo incorpora nuevos elementos que hasta entonces solamente se hallaban de manera puntual en sus viñetas. Se trata, en primer lugar, de retales de revistas, prospectos y anuncios a modo de collage, muy a menudo con figuras femeninas o asociadas a las mujeres (muchas de ellas recortadas de revistas o catálogos antiguos dirigidos al público femenino), que son incorporados en sus relatos del día a día. Se intuye, visto con perspectiva, que Doucet empezaba a introducir el collage a su estilo artístico, aunque esto no se hará patente hasta después de su abandono del dibujo como medio de expresión. También cobra importancia la experimentación gráfica, con la presencia de marcos que envuelven las viñetas, las separan por criterios temáticos o simplemente artísticos y resaltan su contenido. En tercer lugar, incorpora diferentes tipografías, siempre manuales, que en ocasiones se tornan caóticas e incluso dificultan en cierta medida la lectura. Cuenta la leyenda que las personas encargadas del lettering en su versión inglesa, entre las que se encuentra Chris Ware, acabaron agotadas por la cantidad de material que tuvieron que transcribir (Létourneau, 2019). Por último, entremezcla la incorporación de collage y la experimentación tipográfica con la creación de palabras mediante la mezcla de retales de diferentes fuentes, a imagen y semejanza de las notas amenazantes de las películas norteamericanas o, más concretamente, a los fanzines punk (Triggs, 2006).

Llegados a este punto, nos podemos preguntar si realmente se trata de un cómic, algo que también se podría plantear con respecto a su obra posterior. A pesar de que la definición del cómic es muy amplia y puede referirse a diferentes realidades (desde el lenguaje y el medio hasta el género), este álbum cumple con varios de los requisitos, en particular con el contenido de imágenes seriado que explica una historia y con el hecho de que esta esté dibujada (McCloud, 1994). En cambio, otros aspectos señalan en la dirección opuesta: la premeditada ausencia de viñetas, la práctica desaparición de los bocadillos, la presencia de un gran número de re- tales a modo de collage, etcétera. De todos modos, como argumenta Moore, esta pregunta no se hace cuando se trata de un artista consagrado y sí cuando la que lo lleva a la práctica es una dibujante, por más que Doucet sea considerada una autora referente en el ámbito del cómic (Moore, 2018:55).

\section{Elle Humour: aterriza como puedas}

Con Elle Humour Julie Doucet empieza su salida planificada del mundo del cómic. Se trata de un libro publicado por Picture Box, una editorial centrada en publicaciones de arte, no solamente en cómic o ilustración. Con ello, se distancia de sus editores anteriores, particularmente de Drawn \& Quarterly y L'association, que habían publicado hasta la fecha la mayor parte de sus trabajos en inglés y francés, respectivamente. Esta salida es significativa porque se dirige hacia editoriales donde el cómic no es central y pueden acoger su faceta más relacionada con el arte, abstracto o no, y poesía visual. Cabe decir que esta publicación es, de todas las reseñadas, la que más se distancia de la narratividad y también de la idea de conjunto de mayor o menor coherencia estilística.

Elle Humour está organizado de manera un tanto caótica. Se trata de hojas dobles sin numerar, algunas de las cuales se pueden abrir y muestran material adicional. El contenido se organiza por semejanza en el diseño y, en algunos casos, se puede intuir una cierta narratividad. La presencia del collage es mucho mayor que en 365 Days. También se introducen diseños abstractos y formas orgánicas que recuerdan a cuerpos humanos, con cierta presencia de sexualidad, lo que guarda relación con la exploración de las fronteras del cuerpo humano que había llevado a cabo en su obra anterior. En el apartado textual, Doucet extiende el uso del collage a la mezcla de idiomas y a la composición de frases, con un significado final entre lo absurdo y la escritura automática, rehuyendo de una interpretación unívoca. Este es el caso de la figura 3, donde los textos y la imagen no tienen por qué guardar relación, al igual que sucede 


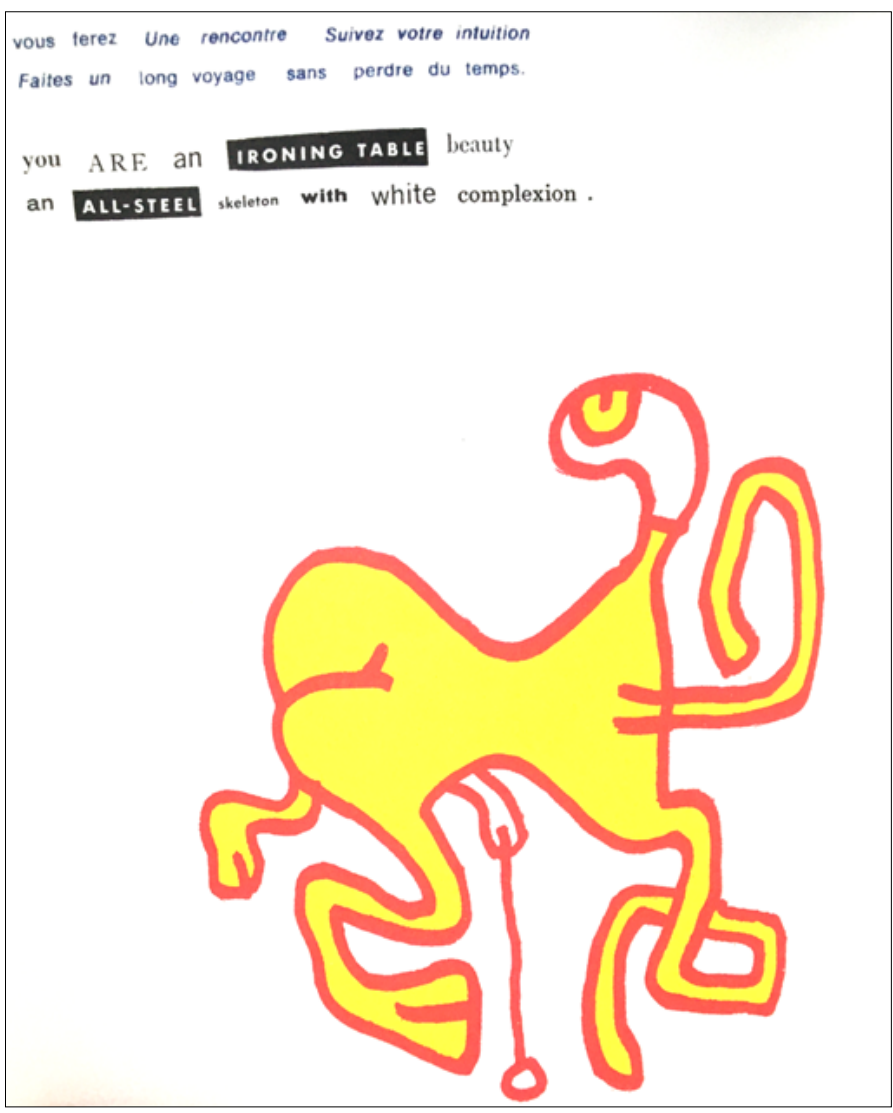

Figura 3. You are an ironing table Fuente: Doucet, 2006, pág. 111

en las páginas anteriores y posteriores, donde se puede especular con una cierta narratividad acerca del amor, el sexo y la soledad.

Rehuyendo de una representación reconocible y una cierta narratividad, Doucet exige un mayor compromiso del público lector, que es ahora el que tiene que interpretar lo que tiene entre sus manos. Como álbum fuera de la órbita de las editoriales especializadas en cómic y, seguramente, con una distribución diferente, su lectura no pasa necesariamente por una interpretación en términos narrativos. En ocasiones, ello implica la lectura de collages de textos con diferentes orígenes, que a menudo no siguen un orden lógico o no transmiten, intencionadamente, un mensaje claro. En otras ocasiones, el mensaje es inteligible, pero absurdo, como los fragmentos dedicados a las bolsas, las sillas o las herramientas, que parece que tengan un objetivo meramente representativo o directamente se trata de dibujos abstractos o formas geométricas.

\section{My new New York Diary: un antes y un después}

Con la publicación de My new New York Diary (2010), Doucet se enfrenta de nuevo al relato en forma de diario que tanto ha caracterizado su obra en el pasado. Esta obra supone una nueva ruptura en la obra de Doucet en tanto que se edita de manera conjunta al videocómic creado por Michel Gondry, basado al mismo tiempo en el cómic de Doucet. En este caso, Doucet ejerció de ella misma, eso sí, a regañadientes, en los decorados que previamente había diseñado. No obstante, parece que este encargo es el que representa un antes y un después en la vida artística de Julie Doucet. En alguna entrevista ha reconocido que su agotamiento personal y artístico tiene origen, en parte, en este proyecto, para el que invirtió una gran cantidad de tiempo y esfuerzo, mucho más del que preveía en un principio. Además, es el último proyecto en el que trabaja que se puede identificar como cómic, pese a que desde el año 1997 venía advirtiendo que su último trabajo en este ámbito era inminente. De hecho, en la propia historia, incluso en la misma portada, se intuye que no se encontraba a gusto con el proyecto de Gondry, algo que confirman algunas intervenciones posteriores de la misma autora (Moore, 2018; Mok, 2019; Small Press Expo, 2018).

Se puede decir que este cómic sigue en la línea de lo autobiográfico y confesional reseñado anteriormente, aunque el contenido es menos comprometido que el que aparece en 365 days, y mucho menos que en su anterior My New York Diary. En ambos casos se trataba de bitácoras mucho menos organizadas, más caóticas. A pesar de ello, puede que se trate de uno de los álbumes en los que el componente autobiográfico es más certero, dado que en los anteriores Doucet jugaba con el plano de lo real y la ficción sin dar pistas al público lector de dónde terminaba una cosa y empezaba 


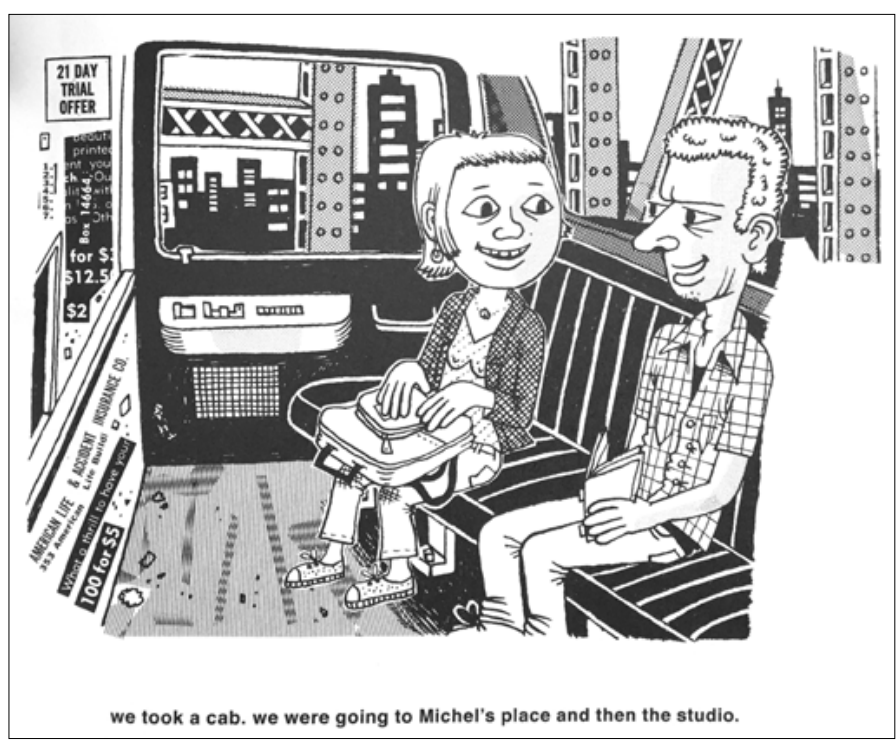

Figura 4. New York Taxi

Fuente: Doucet, 2010, pág. 38

la contraria. La diferencia con su obra autobiográfica anterior es que en esta obra el guion sí que tiene una finalidad, un principio y un fin: el proceso por el cual Michel Gondry le pide participar en su proyecto audiovisual, la grabación de este y las anécdotas que la rodean en la ciudad de Nueva York y, finalmente, la vuelta a Québec.

Desde el punto de vista estilístico y de organización de las viñetas existen varias diferencias entre $M y$ New York Diary y My new New York Diary. En primer lugar, Doucet presenta ya un estilo más maduro, menos oscuro y abigarrado, que en parte había adelantado en El caso de Madame Paul. En esta ocasión, las viñetas son mucho más grandes, de una página cada una, en formato apaisado, y el texto aparece tanto en bocadillos como, principalmente, al pie de la ilustración, a modo de las antiguas aleluyas. La presentación de la propia Julie es mucho más clara y definida que la que encontramos, por ejemplo, en Dirty Plotte. La temática, aunque sigue estando basada en la vida cotidiana de Julie, sigue un orden más determinado que en otras de sus obras. Pese a ello, el guion, centrado en el proceso de producción del proyecto audiovisual, es poco relevante en comparación con su obra anterior.
Incluye trozos de publicaciones y anuncios, uso de tramas y sombreados predibujados que aún no había incorporado, así como algunas páginas dibujadas por Michel Gondry

\section{Carpet Sweeper Tales: ¿Cómic? ¿Fotonovela? Read it out loud}

Con la publicación de Carpet Sweeper Tales (2016) Doucet nos conduce a su última reinvención en términos de ruptura con el cómic establecido. El álbum, en un formato más reducido que sus anteriores álbumes, vuelve a estar editado por su editorial de cabecera, la canadiense Drawn \& Quarterly. Con ello es palpable la diferencia con sus dos obras anteriormente referenciadas, que vistas con perspectiva suponen un paréntesis en su carrera artística. Esta editorial, además de ser la que la dio a conocer durante los años 90, está inconfundiblemente relacionada con el cómic, por si a alguien le quedaba alguna duda del tipo de material que presenta. Ya en la portada y en la contraportada Doucet ofrece un avance de lo que es el álbum: fotos en blanco y negro de personajes más o menos anónimos procedentes revistas de los años 50 y 60 de los que surgen unos bocadillos repletos de tipografías propias de la época que no parecen tener ningún sentido, se mire como se mire.

De hecho, esta es la intención de Julie Doucet: utilizar todos los elementos que caracterizan el cómic para desposeerlos de significado, y además publicarlo en una editorial de referencia mundial en el ámbito del cómic. En primer lugar, el dibujo, que en 365 Days aún era protagonista, desaparece de las páginas. Solamente representa a los personajes con recortes de fotonovelas italianas, a partir de los cuales teje un relato secuencial creado con textos procedentes de revistas de los años 50 como Home and Gardens o Pack-o-Fun (Small Press Expo, 2018). El problema es que el discurso que se espera encontrar en los bocadillos desprovee a las imágenes de tal narratividad, sometiéndola al absurdo. Además, lo hace también con recortes, con cuidadas ti- 
pografías que se entremezclan para componer mensajes que la autora, ya desde las primeras páginas, indica que se han de leer en voz alta, lo que acerca el mensaje a simples onomatopeyas, un lenguaje musicado o, como ella misma define, onomatopoética (Mok, 199) o poesía sonora (Small Press Expo, 2018). Queda, por tanto, sometido a la interpretación del público lector.

Por poner un ejemplo, en la historieta titulada «Stop!!!!!!!!??» todos los diálogos se componen de signos de puntuación: puntos, comas, comillas, exclamaciones, etc. Incluso el relato de lo que parece ser la narración externa sigue este estilo (Doucet, 2016: 117). Aún así, es posible identificar que existe un conflicto de pareja, que se da mayoritariamente en un vehículo, y cuál puede ser su origen. En este sentido, el conflicto de pareja se puede seguir en otros apartados, como el que se origina en «Scott's True Temper» o en «Brdd and Catalma». La interpretación de dichos conflictos, sin embargo, depende de cómo se interprete el mensaje, puesto que el papel de intérprete, nuevamente, se presupone activo (Rudick, 2016).

Todo ello acerca la última obra de Doucet a lo que se ha venido en denominar poesía gráfica o incluso có-

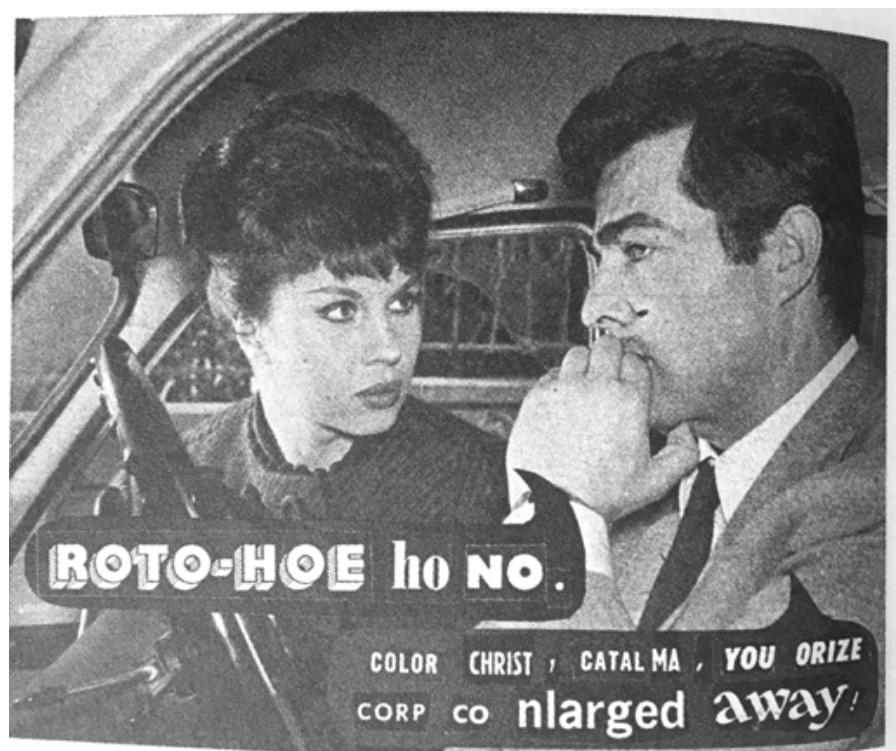

Figura 5. Brdd and Catalma Fuente: Doucet, 2017, pág. 86 mic abstracto, más cuando el objetivo primero, según la propia autora, es no comunicar y hacerlo a partir de imágenes que retrotraen al público lector al pasado, como crítica a la sobreexposición de imágenes en la que vivimos (Small Press Expo, 2018). Con este ejercicio estilístico y lingüístico, Doucet se aproxima al concepto de tebeos raros que acuñó Álvaro Pons (2018), en los que se puede detectar la huída consciente de la función narrativa y una experimentación con los límites del lenguaje y las posibilidades creativas de la historieta.

\section{Conclusiones}

Julie Doucet ha demostrado a lo largo de su carrera que no es una autora que se estanque en un estilo y unas formas inamovibles. Más bien parece que su carrera se caracterice por la experimentación artística, lejos de lo que sería una dedicación al cómic con un estilo invariable y fácilmente reconocible. Así, durante los últimos años ha ido enriqueciendo sus publicaciones con prácticas que suponen una innovación respecto de sus primeras obras, pero que al mismo tiempo pueden suscitar en el público lector una sensación de sorpresa al ver la evolución de sus publicaciones, al mismo tiempo que exige una mayor atención y dedicación para interpretarlas.

Esta evolución se debe contextualizar en el seno de una crisis profesional y artística que la llevó a abandonar el cómic como medio de expresión a principios del siglo XXI. En parte, se trata de un movimiento contra un universo del cómic altamente masculinizado y con unas lógicas de producción y reproducción que acabaron conduciéndola al agotamiento laboral y creativo. A partir de esta crisis, Doucet ha transitado por diferentes caminos rupturistas que van des de la creación audiovisual o el collage, hasta la innovación en el lenguaje, pasando por la introducción de la poesía gráfica, el absurdo y la experimentación sonora y audiovisual.

Así, en 365 Days abordó la ruptura discursiva de los hechos representados, el storytelling en términos cinematográficos, que dejan de ser de naturaleza notable o extraordinaria y con un hilo argumental más o menos 
claro y tendente al clímax, para centrarse en la aburrida rutina diaria de una artista plástica en Montreal. Más tarde, rompió con el dibujo antropomorfo para utilizar elementos que anteriormente ya había incorporado en sus álbumes, como el collage, el dibujo abstracto o la poesía gráfica. Este es el caso de Elle Humour, una obra donde se pueden hallar poesía gráfica y visual y abstracción junto a collages y dibujos orgánicos que, con algo de imaginación, se pueden interpretar como formas humanas. Con My new New York Diary quebrantó las fronteras del cómic como objeto impreso y se introdujo como dibujante en un cómic autobiográfico, a la par impreso y animado, que contaba con su propio proceso de creación, desde la llamada del editor hasta el final del proceso de producción. $\mathrm{Y}$, en los últimos años de su carrera, aún afronta dos rupturas más. La primera es la del abandono del dibujo como elemento central del cómic, para adoptar el collage y la utilización de recursos externos reciclados, en este caso la fotonovela y las revistas de mediados del siglo XX en los casos de Elle Humour y Carpet Sweeper Tales. La segunda es la ruptura del lenguaje figurativo del cómic, que deja de ser inteligible y da paso al lenguaje del absurdo, la repetición y la recreación de una sonoridad que trasciende las fronteras de los idiomas, algo que, de momento, supone su última aportación al cómic.

\section{Bibliografía}

Brown, Andy. «Heroine». Montreal Review of Books. Spring, 2001, https://mtlreviewofbooks.ca/reviews/the-madame-paul-affair/ Recuperado el 1 de diciembre de 2020.

Byrn Køhlert, Frederik. «Female grotesques: carnivalesque subversion in the comics of Julie Doucet», Journal of Graphic Novels and Comics, 3(1), 2012, pp. 19-38. Byrn Køhlert, Frederik. Serial Selves: Identity and Representation in Autobiographical Comics, New Brunswick (EUA): Rutgers University Press, 2019.

Constenla, Teresa. Julie Doucet: «Algunas veces me expuse demasiado», El País (en línea), 2020, https:/ / elpais.com/cultura/2017/11/24/actualidad/1511551879_ 303636.html Recuperado el 27 de octubre de 2020.

Cormier-Larose, Catherine. Manquez de regard: enjeux intermédiatiques du texte et de l'image cher.Julie Doucet et Ken Lurn (Trabajo de Final de Máster), Montreal: Université de Montréal, 2009.

Dagilis, Andrew. «Julie Doucet's Secretions», The Comics Journal, 1991, 141, pp. 98-105.

Doucet, Julie. 365 days. A diary by Julie Doucet. Montreal: Drawn and Quarterly, 2007.

Doucet, Julie. Elle Humour. New York: Picture Box, 2006

Doucet, Julie. My new New York Diary. Brooklyn: Picturebox Inc., 2010.

Doucet, Julie. Cómics 1986-1993, Logroño: Fulgencio Pimentel, 2015.

Doucet, Julie. Carpet Sweeper Tales, Montreal: Drawn and Quarterly, 2016.

Doucet, Julie. Cómics 1994-2016, Logroño: Fulgencio Pimentel, 2017.

Dumez, Philippe. «Les années Julie», Pastis (en línea), 2001, http://www.pastis.org/jade/coibin/reframe. pl?http://www.pastis.org/Gpiedssousterre/nov01/ juliedoucet.htm Recuperado el 9 de octubre de 2020.

Esteban, Mari Luz. «Antropología encarnada. Antropología desde una misma», Papeles del CEIC, 12, 2004, pp. 1-21.

Galvan, Margaret. «From Julie Doucet to Gabrielle Bell. Feminist Genealogies of Comic Anthologies», The comics of Julie Doucet and Gabrielle Bell. A place inside yourself. Ed. Tahneer Oksman y Seamus O’Malley. Jackson: University Press of Mississipi, 2019, pp 3-22.

Jennings, Dana. Drawn and Quarterly's Cartoonist Mystique. The New York Times. AR, 1:20-21.

Juno, Andrea. Dangerous Drawings: Interviews from the Subterranean World of Comix and Graphic Artists. New York: Juno Books, 1997.

McCloud, Scott. Understanding Comics. The invisible art. New York: Harper Perennial, 1994.

Létourneau, Sophie. «On ne casera pas Julie Doucet». Lettres québécoises, 175, 2019, pp. 84-87. 
Mengual, Magda. «Feminitat i feminisme en l'obra de Julie Doucetı (Trabajo de Final de Máster), València: Universitat de València, 2020.

Merino, Ana. «Territorialidad femenina: reflexiones sobre el impacto underground y post-underground». Diez ensayos para pensar el cómic. Ed. Ana Merino. León: Servicio de Publicaciones de la Universidad de León, 2017, pp. 113-133.

Miller, Ann i Pratt, Murray (2004). «Transgressive Bodies in the work of Julie Doucet, Fabrice Neaud and Jean-Christophe Menu: Towards a Theory of the 'AutobioBD'», Belphegor, Litterature Populaire et Culture Médiatique, 4(1), 2004 (en línea) https:/ / dalspace.library. dal.ca/bitstream/handle/10222/47696/04_01_Miller_trnsgr_en_cont.pdf? sequence $=1$ \&isAllowed $=\mathrm{y}$ Recuperado el 13 de octubre de 2020.

Mok, Annie. «»The Starting Point»: An Interview with Julie Doucet» The comics of Julie Doucet and Gabrielle Bell. A place inside yourself. Ed. Tahneer Oksman y Seamus O’Malley. Jackson: University Press of Mississipi, 2019, pp. 197-205.

Moore, Anne Elizabeth. Sweet Little Cunt: The Graphic Work of Julie Doucet. Minneapolis: Uncivilized books, 2018.

Oksman, Tahneer. «Introduction» The comics of Julie Doucet and Gabrielle Bell. A place inside yourself. Ed. Tahneer Oksman y Seamus O’Malley. Jackson: University Press of Mississipi, 2019a, pp. I-LVI.

Oksman, Tahneer. 〈ڤ〉I Really Had to Reinvent Myself»: An Interview with Julie Doucet». Los Angeles Review of Books, 2019b (en línea), http:/ /staging.lareviewofbooks.org/article/i-really-had-to-reinvent-myselfan-interview-with-julie-doucet Recuperado el 15 de octubre de 2020.
Pons, Álvaro. «Tebeos raros: poéticas y nuevos caminos de la historieta». Claves de la Razón Práctica , 2018, 256, pp. 36-45.

Richardson, Sarah. «A Very Dirty Word. Cuteness as Affective Strategy in the Comics of Julie Doucet». The comics of Julie Doucet and Gabrielle Bell. A place inside yourself. Eds. Tahneer Oksman i Seamus O’Malley. Jackson: University Press of Mississipi, 2019, pp. 97121.

Rudick, Nicole. «Carpet Sweeper Tales», The Comics Journal (en línea), 2016, http://www.tcj.com/reviews/ carpet-sweeper-tales/ Recuperado el 26 de noviembre de 2020.

Small Press Expo. «SPX 2018 Panel - Cutting Up: Julie Doucet's Reinventions From Dirty Plotte to Carpet Sweeper Tales». Youtube, 2018 (en línea) https:// www.youtube.com/watch?v=un8Mxey2oT4 Recuperado el 3 de diciembre de 2020.

Stark, Jessica. «My Most Secret Boredom. (Dis) Affective Narrative in Julie Doucet's «A Day in Julie Doucet's Life» and Hergé's «Adventures with Tintin: The Broken Ear». The comics of Julie Doucet and GabrieIle Bell. A place inside yourself. Eds. Tahneer Oksman y Seamus O’Malley. Jackson: University Press of Mississipi, 2019, pp. 23-46.

Triggs, Teal. «Scissors and Glue: Punk Fanzines and the Creation of a DIYAesthetic», Journal of Design History, 19 (1), 2006, pp. 69-83.

Woodley, Matthew. «Plotte Twists». The Montreal Mirror, 22(1), 2006 (en línea) https://web.archive.org/ web/20080810223933/http:/ /www.montrealmirror.com/2006/062206/cover_art.html Recuperado el 2 de noviembre de 2020 . 